\title{
On the Evaluation of College Teachers YANG Shuo
}

\author{
Jinlin Business and Technology College, ChangChun, 130507
}

yangyu1983@sina.com

Key words: teacher evaluation; teaching quality; problem and countermeasure

\begin{abstract}
Teaching evaluation is an important part in the college teaching management, and of great significance for the quality improvement of teaching. This article analyzes the significance, details and methods of teacher evaluation, and discusses the existing problems and countermeasures.
\end{abstract}

\section{Introduction}

In order to ensure the smooth development of college education, an army of capable, high-quality and high-level teachers must be founded. This is the key condition for the development of college education, and the objective of the college' s personnel management system. A perfect and scientific mechanism of evaluation of college teachers is an all-important means to achieve this objective, and is a necessary measure to improve the teaching quality. The teaching quality is typically evaluated on the basis of teaching effects which in turn results from various factors of the teaching environment such as management level, policy orientation, teacher' s quality, student' $\mathrm{s}$ quality, nature of the discipline or course, training objective, class size, hardware equipment, social demand and personnel system. In order to understand the positive effects of the teaching evaluation, and to exert a correct attitude towards the positive effects and the limitations of "teacher evaluation" , the significance, details, methods, existing problems and countermeasures of teacher evaluation are discussed below ${ }^{[1-5]}$.

\section{Significance of Teacher Evaluation}

The teacher evaluation is of great significance for the improvement of teaching quality. It is shown in numerous researches that the teacher' $s$ teaching quality takes a direct effect on the student' s development, so the teachers are the key to the quality of talent cultivation. Firstly, teacher evaluation is a fundamental work for the introduction of a competitive mechanism into the teaching activity. Nowadays, colleges are faced with immensely different living environment and developing trend compared to ten years ago. On one hand, the college graduates encounter more opportunities and challenges when choosing a career. Their employment and development depend more and more on their personal qualities, abilities and knowledge structure. On the other hand, the educational expenses are no longer borne by the government, but by the students and their own families. Thus, the students and their families care more about the colleges' teaching quality. And the competition among colleges inevitably brings in the competition among teachers within each college. No matter how these individuals compete, teacher evaluation is an essential groundwork and a fundamental criterion for a qualified teacher. Secondly, teacher evaluation not only promotes the teachers' teaching level, but also helps the teachers to discover their deficiencies in teaching activities. Both young and senior teachers should keep improving their teaching skills.

\section{Details of Teacher Evaluation}

Teacher' s ethics. A teacher is a transmitter of knowledge and a model of personal behaviors. The teacher' s professional ethics and responsibility influences both the teaching quality and the students' formation of view of world, life and value. Since the students spend much time with the teacher, the evaluation given by the students can reflect the teacher' $\mathrm{s}$ ethics.

Teaching ability. The teaching ability is embodied in the appropriateness of the teaching 
contents designed by the teacher, in the reflectivity of disciplinary forefront and latest teaching achievement, in the suitability with the level of students taught, in the priority of key points and difficult points, in the appropriateness of the chosen examples, and the in the connection between theory and practice.

Selection of teaching methods and means. The teacher should choose the teaching methods, ways and means on the basis of the course characteristics and the students' level for the purpose of improve the teaching effect. At present, multimedia teaching method centered by the computer has been widely applied and expands the amount of information in the class to a great extent. The new teaching method requires the reorganization of teaching contents, rather than the reproduction of a traditional teaching. If this requirement was not met, the teaching effect wouldn' $t$ be improved, and even may be damaged.

\section{Method of Teacher Evaluation}

Self-evaluation. Self-evaluation refers to the evaluation of the teachers by themselves based on established criteria. It is an important form of educational evaluation, an important means of teacher evaluation, and a process of self-reflection, self-education, and self-development. In the establishment of operable teacher self-evaluation index system, the teachers' individual diversity shall be considered, and the pertinence, flexibility and operability of the evaluation criteria shall be enhanced.

Students' evaluation. Along with the standardization of the evaluation of teachers' professional titles, and many colleges require more and more highly on the teachers' quality, and the students' evaluation is more popularly conducted. The results of students' evaluation have been widely utilized in professional evaluation, curriculum evaluation and teacher evaluation. The students' evaluation provides comparable and identifiable information for teaching administration, and becomes a criterion for the employment and promotion of teachers and the set-up of curriculums. The teachers can improve the curriculum contents and methods on the basis of the results of students' evaluation.

Peer evaluation. Peer evaluation is the evaluation of the colleagues' development and change on the basis of their teaching achievements and the communications with each other. The main body of peer evaluation is a group of teachers in the same or similar discipline. Because the colleagues spend much time together, closely contact with each other and exchange their thoughts, they inevitably evaluates each other. Peer evaluation includes the evaluations of the colleagues' teaching ability, professional ethics and individual mental characteristics.

Expert evaluation. The experts are teachers with strong responsibility and rich teaching experience. The supervising experts can attend classes of different majors and departments in the college. They not only score various aspects of the teaching activity but also put forward the teacher' s shortcomings and defects as well as suggestions for improvement.

\section{Existing Problems and Countermeasures in Teacher Evaluation}

At present, the teacher evaluation in China has the following problems: scientific research is regarded highly rather than teaching ability; the evaluation system is not scientific; evaluators are not professional; and the evaluation theory is not up-to-date. These problems seriously affect the evaluation quality and the improvement of positive attitude of the teachers. Several prominent problems are analyzed as follows:

The evaluation ideas are unreasonable. The present management of evaluation of college teachers still follows the old idea that is to evaluate the teachers' political ideology, professional skills, teaching activities, scientific researches and social services on a periodic base using qualitative and quantitative methods, in order to rank the teachers as Level A, B, C, and D. Then, the evaluation results are directly linked with the teachers' award granting, title appraisal, salary increment, promotion, Communist Party admission, continuous employment, job assignment and bonus. Oriented by this idea of evaluation, the college teachers are busy with project application 
and thesis writing rather than imparting knowledge and educating people.

The evaluation model is unreasonable. At present, China's evaluation model for college teachers are still summative evaluation. Teachers do not welcome it because its reward-punishment nature; principals are confused about the disharmonic atmosphere it brings into the school; supervising agencies are lost at sea because of its inefficiency. Only in a trustful and harmonic atmosphere can the effective teacher evaluation brings about the improvement of the teachers' professional level, and serves the colleges' personnel decisions.

The incentive function is lost due to the lack of feedback in the evaluation procedure. In today' s college teacher evaluation, feedback is one of the weakest sectors. The evaluated teachers tend to know nothing about their evaluation results, or they know only the final score or rating but don' $\mathrm{t}$ know the implications of the results. Neither do they know their own advantages and disadvantages. Feedback of the evaluation results ought to be a great opportunity for the evaluators and teachers to communicate and for the fulfillment of evaluation function. But, the lack of active feedback makes it hard for the college teachers to know the consistency between the organization' $s$ expect and their own performances. This injures the teachers' right to know, and deprives their rights to defend their own opinions on the evaluation results.

The managers are unprofessional. The management departments must be first reformed in the reformation of the old traditional system of teacher evaluation. Only when the management organizations and personnel have the proper idea for teacher evaluation, will the reformation be conducted on a right path.

The criteria, subject, method and result of evaluation must all be improved for the purpose of solving these problems.

The evaluation criteria must be flexible in order to promote the teachers' individual development. Every teacher is quite different in age, knowledge, teaching and researching experience, and professional skill and goal. Some teachers are good at teaching, while others do better in scientific researches. Teachers of different ages, disciplines and genders do their scientific researches in different ways. On one hand, the evaluation should have uniform requirements and criteria from an overall perspective of the college. On the other hand, different evaluation criteria and methods should be applied to different evaluation objects, on the basis of each teacher' s own characteristics, because diversity of teachers needs to be understood and respected. In this way, the teachers' individual strong points will be in full play, and they will develop and improve towards a uniform direction.

The evaluation subjects should be comprehensive in order to evaluate the teachers' work from multiple aspects and angles and to promote their development. The evaluation subjects should include college management personnel, colleagues, parents, community representatives, and students as well as the teachers themselves.

The evaluation method should be flexible and diverse, combining quantitative evaluation and qualitative evaluation, and complementing formal evaluation and informal evaluation with each other. Multiple methods should be applied to the teacher evaluation, due to the diversity of evaluation details and methods and the variation of teachers' quality, ability and performance. In this way, the evaluation will reflect the teachers' conditions comprehensively and correctly, and promote their development with effective measures.

The evaluation results must be processed properly. A proper evaluation should apply proper techniques to avoid the effect of the factors except for the teachers' own personal factors on the evaluation results to the greatest extent, and should re-evaluate the actual results in order to truly discover the teachers' achievements and deficiencies and to help them improve their work.

\section{Conclusion}

With the rapid development of China's higher education cause and the extensive implementation of college teachers' personnel assignment system reform, it is extremely urgent to 
promote the Level of Human Resource Management in colleges. To construct the college teacher performance evaluation system is a systematic project, and needs the comprehensive consideration of various subjective and objective factors, the balancing of different goals and the dynamic perfection of the system. Therefore, it is unrealistic to blindly introduce some existing evaluation systems, and unacceptable to overemphasize the difficulties and to do nothing. Over the years, many colleges and related scholars have been devoted to construct a perfect teacher performance evaluation system, and several relatively systematic and operable teacher performance evaluation systems have been established, but some problems remain unsolved. For instance, as to the design of evaluation index and criteria, how to evaluate the teachers' comprehensive quality and potential such as the professional ethics, humanity spirit, and creativity; how to value both quantity and quality of teaching and research achievement; how to balance the teachers' research performance and teaching achievement; how to distinguish the development characteristics and laws between social science and natural science disciplines; and how to reflect the training and evaluation characteristics of young teachers. In addition, the procedure of evaluation needs to be perfected. In the dominant idea of evaluation and the design of index, the administrative-oriented system must be reformed into an academic-oriented system. The college experts' ability and wisdom must be in full play, and the employment qualification and working performance of teachers at all levels should be objectively and scientifically evaluated. The overall improvement goal is to make the teachers overcome the short-term interest driven disadvantage and to make the researching and teaching not lose their independence, innovation and foresight, guided by the teacher evaluation system. Teachers are the main body of a college, and the direct undertakers of college education. A reasonable evaluation of a college' $s$ teachers not only reflects the actual teaching level of the college, but also promotes the teaching, learning and reforming activities. Since the work of teaching evaluation is very complicated, educators should constantly research, demonstrate and perfect it in order to guarantee its scientificity.

\section{References}

[1] You Hao.A Narrative Inquiry of College English Teachers' Classroom Assessment Knowledge and Practice.Shen yang:LiaoNing Normal University.(2014)

[2] Zhang Weilei.Study of Current Evaluation on College English Teachers.Journal of SYIBE.Vol.21(2014).p.81-88

[3] JinXin,Li Qiuju.Comparison of Self-valuation, Peer-evaluation and Teachers' Evaluation in Basic English Writing.FLC.Vol.12(2015).p.75-81

[4] Huang Jianhui,Hong Ming.Evaluation on NCTQ Teachers' Cultivation Quality and Its Controversy.Studies in Foreign Education.Vol.42(2015).p.109-117

[5] Wang Jufang,Yang Qiulan.Analysis on College English Teachers' evaluation in Task-based Language Teaching.Overseas English.Vol.11(2013).p.134-136 